\title{
Predictive Factors for the Development or Regression of Fatty Liver in Japanese Adults
}

\author{
Katsuhisa Omagari, ${ }^{1 *}$, Shun-ichi Morikawa ${ }^{2}$, Seiko Nagaoka ${ }^{3}$, Yukiko Sadakane', Miki Sato', \\ Mizuho Hamasaki ${ }^{1}$, Shigeko Kato ${ }^{1}$, Jun-ichi Masuda ${ }^{2}$, Masayuki Osabe ${ }^{2}$, Takehiko Kadota ${ }^{3}$, \\ and Keisuke Sera ${ }^{4}$ \\ ${ }^{1}$ Department of Nutritional Science, Faculty of Nursing and Nutrition, University of Nagasaki, \\ Siebold, 1-1-1 Manabino, Nagayo-cho, Nagasaki 851-2195, Japan \\ ${ }^{2}$ Department of Internal Medicine, Mitsubishi Heavy Industries, Ltd., Nagasaki Shipyard and Machinery Works \\ Hospital, 1-73 Akunoura, Nagasaki 850-0063, Japan \\ ${ }^{3}$ Health Service Center, Mitsubishi Heavy Industries, Ltd., Nagasaki Shipyard and Machinery Works Hospital, \\ 1-73 Akunoura, Nagasaki 850-0063, Japan \\ ${ }^{4}$ Department of Orthopedics, Mitsubishi Heavy Industries, Ltd., Nagasaki Shipyard and Machinery Works Hospital, \\ 1-73 Akunoura, Nagasaki 850-0063, Japan
}

Received 28 December, 2008; Accepted 6 January, 2009

\begin{abstract}
Summary Fatty liver is commonly associated with alcohol or metabolic syndrome. We aimed to examine the longitudinal aspects of fatty liver, and clarify the independent predictors for the development or regression of fatty liver. In the present study, the clinical features of 1578 Japanese adults (1208 men and 370 women; 35 to 69 years of age) who visited our center both in 2000 and 2007-2008 were recorded and compared, including liver status diagnosed by ultrasonography. Of the 1578 participants, $217(13.8 \%)$ showed fatty liver development, and $74(4.7 \%)$ showed fatty liver regression. Logistic regression analysis revealed that body mass index and percentage body fat were strongly associated with the development or regression of fatty liver. Metabolic syndrome-related disorders such as serum levels of total cholesterol, triglyceride, uric acid, and fasting blood glucose were also associated with clinical course to some degree. However, the history of alcohol intake, the presence of metabolic syndrome, blood pressure, and habitual physical exercise were not independent predictors for the development or regression of fatty liver. Our present data suggest that control of body weight in men and the percentage body fat in women are particularly important for the prevention or treatment of fatty liver.
\end{abstract}

Key Words: fatty liver, non-alcoholic fatty liver disease, body mass index, percentage body fat, metabolic syndrome

\section{Introduction}

Fatty liver (steatosis) is defined as an accumulation of fat, mainly triglyceride, in liver cells. This disease is commonly

\footnotetext{
*To whom correspondence should be addressed.

Tel \& Fax: +81-95-813-5201

E-mail: omagari@sun.ac.jp
}

associated with alcohol or metabolic syndrome (diabetes mellitus, hypertension, and dyslipidemia) [1]. In particular, non-alcoholic fatty liver diseases (NAFLD) are recognized as the hepatic manifestation of metabolic syndrome and the prevalence of this entity is increasing in many countries [2-4]. In Japan, Kojima et al. [5] reported that the prevalence of fatty liver rose gradually from $12.6 \%$ in 1989 to $30.3 \%$ in 1998 ; this was mainly due to an increase in body mass index (BMI). Hamaguchi et al. [6] reported that 
metabolic syndrome was a risk factor for the development of NAFLD, and conversely, Fan et al. [4] suggested that the presence of NAFLD might predict the development of metabolic syndrome. Lifestyle changes, including weight loss and physical exercise, have been shown to improve the clinical course in NAFLD [3,7].

In our previous study, we examined the frequency of fatty liver diagnosed by ultrasonography (USG) in 3432 Japanese adults who visited Health Service Center, Mitsubishi Heavy Industries, Ltd., Nagasaki Shipyard and Machinery Works Hospital, Nagasaki, Japan for a thorough medical examination between January and December 2000 and found that BMI was the most independent predictor for the presence of fatty liver in both sexes [8]. We further reported that percentage body fat was a useful index to assess the etiology of fatty liver in non-alcoholic and non-overweight participants, particularly women.

In the present study, we aimed to examine the longitudinal aspects of fatty liver in each participant who visited the same health checkup center. We also clarified the independent predictors for the development or regression of fatty liver in non-alcoholic participants.

\section{Materials and Methods}

\section{Study participants}

Of the 3432 Japanese participants who visited the Health Service Center, Mitsubishi Heavy Industries, Ltd., Nagasaki Shipyard and Machinery Works Hospital, Nagasaki, Japan for a thorough medical examination between January and December 2000 (in 2000) [8], 1589 also visited the same Center between April 2007 and March 2008 (in 2007-2008). The medical examination was performed for subjects who visited the hospital voluntarily (most of them were employees or their families) to promote public health through early detection of chronic diseases. Of these 1589 participants, we excluded 6 participants who turned positive for anti-hepatitis $\mathrm{C}$ virus antibody and 5 participants who did not undergo USG in 2007-2008 from the present study. Therefore, the total number of study subjects was 1578 (1208 men and 370 women; mean age, $54.0 \pm 4.7$ years; range, 35 to 69 years). This study was performed according to the principles of the Declaration of Helsinki. The study protocol was approved by the Ethical Committees of Siebold University of Nagasaki and Mitsubishi Heavy Industries, Ltd., Nagasaki Shipyard and Machinery Works Hospital. Informed consent was obtained from all participants.

\section{Data collection and measurements}

The medical examination was performed between 8:0011:00 am after overnight fasting. The information obtained from the medical records for the present study included sex, age, height, body weight, history of alcohol intake, present physical exercise habit, history of medical treatment for hypertension, dyslipidemia, and/or diabetes mellitus, systolic blood pressure (SBP), diastolic blood pressure (DBP), serum levels of aspartate aminotransferase (AST), alanine aminotransferase (ALT), $\gamma$-glutamyl transpeptidase (GGTP), total choresterol (T.Chol.), triglyceride (TG), uric acid (UA), fasting blood glucose (FBG), percentage body fat ( $\%$ fat volume), and liver status by USG.

The history of alcohol intake, present physical exercise habit and history of medical treatment for hypertension, dyslipidemia and/or diabetes mellitus were determined by questionnaire. The history of alcohol intake was divided into three groups as follows: never drinker, heavy drinker (at least $70 \mathrm{~g} /$ day of alcohol intake more than 5 times per week), and moderate drinker (neither never drinker nor heavy drinker). Regarding the present physical exercise habit, participants marked "yes" if they had a habit of physical exercise such as jogging, walking, or playing tennis, golf, or badminton. Regarding the history of medical treatment for hypertension, dyslipidemia and/or diabetes mellitus, participants marked "yes" if they had been receiving medical treatment for such diseases.

The body mass index (BMI) was calculated as body weight $(\mathrm{kg})$ divided by height $\left(\mathrm{m}^{2}\right)$. Overweight was defined as a BMI of $\geq 25 \mathrm{~kg} / \mathrm{m}^{2}$ [9]. The percentage body fat measurement was performed using a bipedal bioimpedance instrument (Body Fat Analyzer TBF-202; Tanita, Tokyo, Japan). Obesity was defined for Japanese adults as $\geq 25 \%$ body fat for men and $\geq 30 \%$ body fat for women [8].

Abdominal ultrasonography was performed by clinical hepatogastroenterologists or trained technicians without knowledge of the anthropometric and laboratory data. When USG was performed by a trained technician, one hepatogastroenterologist reviewed the stored ultrasonographic images and made the final diagnosis. The diagnosis of fatty liver by USG (Aloka Pro Sound SSD-4000; Aloka, Tokyo, Japan) was based on the findings of "bright liver" (increased echogenicity) with "liver-kidney contrast" (increased echo level of the liver compared with the right kidney). "Vascular blurring" (blurring of the hepatic vein) and "deep attenuation" (attenuation of the echo level in the deep region of the liver) were also seen in many cases, but their absence did not exclude the diagnosis of fatty liver.

The standard Japanese criteria for the diagnosis of metabolic syndrome are as follows. The presence of visceral fat accumulation (defined as waist circumference $\geq 85 \mathrm{~cm}$ for men and $\geq 90 \mathrm{~cm}$ for women) is an indispensable factor, with any two or more of the following criteria: (1) a high serum level of triglyceride $(\geq 150 \mathrm{mg} / \mathrm{dL}$ or $\geq 1.7 \mathrm{mmol} / \mathrm{L}$ ) and/or low serum level of high-density lipoprotein (HDL) cholesterol $(<40 \mathrm{mg} / \mathrm{dL}$ or $<1.03 \mathrm{mmol} / \mathrm{L})$ or receiving specific treatment for these abnormalities; (2) high blood pressure ( $\mathrm{SBP} \geq 130 \mathrm{mmHg}$ and/or $\mathrm{DBP} \geq 85 \mathrm{mmHg}$ ) or 
receiving specific treatment for hypertension; (3) high FBG concentration ( $\geq 110 \mathrm{mg} / \mathrm{dL}$ or $\geq 6.11 \mathrm{mmol} / \mathrm{L}$ ) or receiving specific treatment for glucose abnormality [10]. Because waist circumference and serum level of HDL cholesterol were not available in our study subjects, we substituted a BMI $\geq 25 \mathrm{~kg} / \mathrm{m}^{2}$ for waist circumference, and omitted the HDL cholesterol. Therefore, we defined a "tentative metabolic syndrome" as follows: BMI $\geq 25 \mathrm{~kg} / \mathrm{m}^{2}$ plus at least two of the following three factors: (1) a high serum level of triglyceride $(\geq 150 \mathrm{mg} / \mathrm{dL})$ or receiving specific treatment for triglyceride abnormality; (2) high blood pressure (SBP $\geq 130 \mathrm{mmHg}$ and/or DBP $\geq 85 \mathrm{mmHg}$ ) or receiving specific treatment for hypertension; (3) high FBG concentration $(\geq 110 \mathrm{mg} / \mathrm{dL})$ or receiving specific treatment for glucose abnormality. Serum level of low-density lipoprotein (LDL) cholesterol was also unavailable in our study population.

\section{Comparison of data between 2000 and 2007-2008}

In the comparison of each individual participant's data between 2000 and 2007-2008, "\% change" in BMI and the percentage body fat was calculated as follows: $\{[$ (data in 2007-2008)-(data in 2000)]/data in 2000$\} \times 100$. "Change" in blood pressures and laboratory data was calculated as follows: (data in 2007-2008) - (data in 2000). Regarding alcohol behavior, participants were divided into following four groups: non-drinker \{never drinker or occasional drinker (1-4 times per week) in 2000 [8], and never drinker in 2007-2008\}; continuous drinker \{almost every day drinker (at least $23 \mathrm{~g} /$ day of alcohol intake 5-7 times per week) in 2000 [8], and heavy drinker or moderate drinker in 2007-2008\}, former drinker (almost every day drinker in 2000 and never drinker in 2007-2008); and others (neither non-drinker, continuous drinker, nor former drinker).

\section{Statistical analysis}

Data were expressed as mean \pm standard deviation (SD) or median (range). Differences between groups were examined for statistical significance using the two-tailed Mann-Whitney $U$ test, Wilcoxon signed-rank test, chi-square test, or Fisher's exact probability test. Multivariate analysis for the development or regression of fatty liver was performed for variables that were significant in univariate analyses using logistic regression analysis. Correlations were examined by linear regression analysis using the coefficient of correlation. All data analyses were performed using SPSS statistical package, version 16.0J (SPSS, Inc., Chicago, IL) on a computer with a Windows operating system. A $p$-value less than 0.05 was considered statistically significant.

\section{Results}

Clinical and laboratory features of participants in 20072008

The participants' age in 2007-2008 was significantly higher in men $(54.4 \pm 4.7$ years; range, 41 to 69 years) than in women $(52.7 \pm 4.6$ years; range, 35 to 65 years $)$ $(p<0.001)$. The number and frequency of participants for each clinical and laboratory feature are shown in Table 1. Of the 1578 participants, fatty liver was diagnosed by USG in $501(31.7 \%)$. Of the 370 women in the study, $247(66.8 \%)$ were obese ( $\geq 30 \%$ fat volume).

Fatty liver was more frequently seen in men and overweight as well as obese participants. Systolic and diastolic blood pressure, serum levels of AST, ALT, GGTP, T.Chol, TG, UA, and FBG were higher in participants with fatty liver than in those with non-fatty liver. Participants who have "tentative metabolic syndrome" and who had been receiving treatment for hypertension, dyslipidemia and/or diabetes mellitus were more frequently found in the fatty liver group. In contrast, there were no significant differences in age and the proportion of alcohol drinker between the fatty liver and non-fatty liver groups of participants. Physical exercise habit was more common in the non-fatty liver group (Table 2).

\section{Comparison of clinical and laboratory features between 2000 and 2007-2008}

The median interval in thorough medical examinations between 2000 and 2007-2008 was 84.0 months (range, 76 to 98 months). Between 2000 and 2007-2008, the change in median body weight, BMI, and percentage body fat was $+0.8 \mathrm{~kg}$ (range, -16.4 to $+19.8 \mathrm{~kg}$ ), $+0.4 \mathrm{~kg} / \mathrm{m}^{2}$ (range, -5.4 to $+7.6 \mathrm{~kg} / \mathrm{m}^{2}$ ), and $+0.2 \%$ (range, -11.2 to $+21.7 \%$ ), respectively. Body mass index, percentage body fat, serum levels of AST, ALT, GGTP, T.Chol., TG, UA, and FBG were higher in participants in 2007-2008 than in 2000. In contrast, DBP was lower in 2007-2008 than in 2000 (Table 3). In 2000, fatty liver was diagnosed by USG in 358 of the 1578 participants. Of these 358 participants, 284 had fatty liver in 2007-2008. Of the 1220 participants who did not have fatty liver in 2000, 217 had fatty liver in 2007-2008 (Fig. 1).

\section{Clinical and laboratory features of participants who were classified as non-drinkers}

To determine the clinical and laboratory features of fatty liver and non-fatty liver in non-alcoholic participants, the data from 346 participants who were classified as nondrinkers [never drinker or occasional drinker (1-4 times per week) in 2000 [8] and never drinker in 2007-2008] were analyzed. Of these 346 participants, 102 had fatty liver in 2007-2008 and fatty liver was more frequently seen in men, overweight, and obese participants. Systolic and diastolic 
Table 1. Number and frequency of participants for each clinical and laboratory feature in 2007-2008 $(n=1578)$

\begin{tabular}{|c|c|c|}
\hline Feature & No. of subjects & Frequency $(\%)$ \\
\hline Fatty liver by USG & 501 & 31.7 \\
\hline \multicolumn{3}{|l|}{ Alcohol consumption } \\
\hline Never drinker & 365 & 23.1 \\
\hline Drinker & 1098 & 69.6 \\
\hline Heavy drinker & 71 & 4.5 \\
\hline ND & 44 & 2.8 \\
\hline \multicolumn{3}{|l|}{ Physical exercise habit } \\
\hline Yes & 536 & 34.0 \\
\hline No & 1031 & 65.3 \\
\hline ND & 11 & 0.7 \\
\hline $\mathrm{BMI} \geq 25 \mathrm{~kg} / \mathrm{m}^{2}$ & 414 & 26.2 \\
\hline$\%$ fat volume excess (men and women) & 596 & 37.8 \\
\hline$\%$ fat volume $\geq 25 \%$ (men) & 349 & 28.9 \\
\hline$\%$ fat volume $\geq 30 \%$ (women) & 247 & 66.8 \\
\hline $\mathrm{SBP} \geq 130 \mathrm{mmHg}$ & 505 & 32.0 \\
\hline $\mathrm{DBP} \geq 85 \mathrm{mmHg}$ & 194 & 12.3 \\
\hline $\mathrm{AST} \geq 34 \mathrm{IU} / \mathrm{L}$ & 145 & 9.2 \\
\hline $\mathrm{ALT} \geq 43 \mathrm{IU} / \mathrm{L}$ & 158 & 10.0 \\
\hline GGTP $\geq 48$ IU/L & 558 & 35.4 \\
\hline T.Chol. $\geq 220 \mathrm{mg} / \mathrm{dL}$ & 637 & 40.4 \\
\hline $\mathrm{TG} \geq 150 \mathrm{mg} / \mathrm{dL}$ & 393 & 24.9 \\
\hline $\mathrm{UA} \geq 7.6 \mathrm{mg} / \mathrm{dL}$ & 167 & 10.6 \\
\hline $\mathrm{FBG} \geq 110 \mathrm{mg} / \mathrm{dL}$ & 302 & 19.1 \\
\hline Tentative metabolic syndrome & 164 & 10.4 \\
\hline Receiving treatment for $\mathrm{HT}, \mathrm{DL}$, and/or DM & 430 & 27.2 \\
\hline
\end{tabular}

USG, ultrasonography; ND, not described; BMI, body mass index; SBP, systolic blood pressure; DBP, diastolic blood pressure; AST, aspartate aminotransferase; ALT, alanine aminotransferase; GGTP, gamma-glutamyl transpeptidase; T.Chol., total cholesterol; TG, triglyceride; UA, uric acid; FBG, fasting blood glucose; HT, hypertension; DL, dyslipidemia; DM, diabetes mellitus.

blood pressures, serum levels of AST, ALT, GGTP, TG, UA, and FBG were higher in participants with fatty liver than in those without fatty liver. Participants who had "tentative metabolic syndrome" and who had been receiving treatment for hypertension, dyslipidemia and/or diabetes mellitus were more frequently found in the fatty liver group. In contrast, there were no significant differences in age and serum level of T.Chol. between participants with and without fatty liver. Physical exercise habit was more common in the non-fatty liver group (Table 4). In 2000, fatty liver was diagnosed in 73 of the 346 participants who were classified as nondrinkers. Of these 73 participants, 12 no longer had evidence of fatty liver in 2007-2008. Of the 273 participants who were classified as non-drinkers and who did not have fatty liver in 2000, 41 had fatty liver in 2007-2008 (Fig. 2).
Comparison of clinical and laboratory features of fatty liver and non-fatty liver in 2007-2008

Men and women were separately analyzed in comparisons of clinical and laboratory features of fatty liver and non-fatty liver in 2007-2008 in participants who did not have fatty liver in $2000(n=1220)$. Body mass index in $2000, \%$ change in BMI, percentage body fat in $2000, \%$ change in percentage body fat, TG in 2000 , change in UA, and change in FBG were higher in participants who had fatty liver in 2007-2008 in both sexes. Also, the development of "tentative metabolic syndrome" was more common in participants who had fatty liver in 2007-2008 in both sexes. Systolic blood pressure and T.Chol. in 2000, and change in TG were higher in men who had fatty liver in 2007-2008. Participants who had been receiving specific treatment for hypertension, dyslipidemia and/or diabetes mellitus were more frequent 
Table 2. Comparison of clinical and laboratory features of fatty liver and non-fatty liver in 2007-2008 $(n=1578)$

\begin{tabular}{lllr}
\hline Feature & $\begin{array}{l}\text { Fatty liver } \\
(n=501)\end{array}$ & $\begin{array}{l}\text { Non-fatty liver } \\
(n=1077)\end{array}$ & $<0.001$ \\
\hline Men/women & $427 / 74$ & $781 / 296$ & 0.514 \\
Age (years) & $55(41-69)$ & $55(35-69)$ & 0.642 \\
Alcohol (heavy/moderate/never drinker) & $22 / 356 / 107$ & 0.001 \\
Physical exercise habit (yes/no) & $138 / 359$ & $49 / 742 / 258$ & $<0.001$ \\
BMI (kg/m²) & $25.1(17.4-46.0)$ & $398 / 672$ & $<0.001$ \\
\% fat volume (men) & $25.7(14.0-42.0)$ & $22.3(12.8-32.8)$ & $<0.001$ \\
\% fat volume (women) & $34.3(22.5-53.8)$ & $26.2(6.6-41.3)$ & $<0.001$ \\
SBP (mmHg) & $126(88-161)$ & $121(81-177)$ & $<0.001$ \\
DBP (mmHg) & $76(54-101)$ & $74(45-105)$ & $<0.001$ \\
AST (IU/L) (NV: 13-33) & $25(9-137)$ & $21(11-69)$ & $<0.001$ \\
ALT (IU/L) (NV: 8-42) & $31(2-169)$ & $19(5-123)$ & $<0.001$ \\
GGTP (IU/L) (NV: 10-47) & $50(12-850)$ & $30(5-701)$ & 0.003 \\
T.Chol. (mg/dL) (NV: 130-219) & $216(150-370)$ & $211(115-319)$ & $<0.001$ \\
TG (mg/dL) (NV: 46-149) & $132(42-1116)$ & $92(20-990)$ & $<0.001$ \\
UA (mg/dL) (NV: 2.6-7.5) & $6.3(0.7-12.0)$ & $5.5(1.8-11.8)$ & $<0.001$ \\
FBG (mg/dL) (NV: 70-109) & $103(76-295)$ & $97(66-221)$ & $<0.001$ \\
Tentative metabolic syndrome (present/absent) & $131 / 370$ & $33 / 1044$ & $<0.001$ \\
Receiving treatment for HT, DL, and/or DM (yes/no) & $185 / 316$ & $245 / 832$ & \\
\hline Age, BMI\% $\%$ &
\end{tabular}

Age, BMI, \% fat volume, blood pressure and biochemical data are expressed as median (range).

$\mathrm{NV}$, normal value. Refer to the legend of Table 1 for other abbreviations.

Table 3. Comparison of clinical and laboratory features between 2000 and 2007-2008 $(n=1578)$

\begin{tabular}{lllr}
\hline Feature & 2000 & $2007-2008$ & $p$ \\
\hline BMI $\left(\mathrm{kg} / \mathrm{m}^{2}\right)$ & $22.8(14.8-45.1)$ & $23.1(12.8-46.0)$ & $<0.001$ \\
\% fat volume (men) & $22.2(9.2-52.6)$ & $22.4(7.0-42.0)$ & 0.008 \\
\% fat volume (women) & $26.9(11.5-49.8)$ & $27.6(6.6-53.8)$ & 0.008 \\
SBP (mmHg) & $121(79-199)$ & $123(81-177)$ & 0.937 \\
DBP $(\mathrm{mmHg})$ & $76(43-121)$ & $75(45-105)$ & $<0.001$ \\
AST (IU/L) & $20(9-153)$ & $22(9-137)$ & $<0.001$ \\
ALT $(\mathrm{IU} / \mathrm{L})$ & $19(2-130)$ & $21(4-169)$ & $<0.001$ \\
GGTP $(\mathrm{IU} / \mathrm{L})$ & $28(6-438)$ & $36(5-850)$ & $<0.001$ \\
T.Chol. (mg/dL) & $207(106-334)$ & $212(115-370)$ & $<0.001$ \\
TG $(\mathrm{mg} / \mathrm{dL})$ & $93(22-1516)$ & $104(20-1116)$ & $<0.001$ \\
UA $(\mathrm{mg} / \mathrm{dL})$ & $5.5(1.0-10.0)$ & $5.8(0.7-12.0)$ & $<0.001$ \\
FBG $(\mathrm{mg} / \mathrm{dL})$ & $94(65-243)$ & $99(66-295)$ & $<0.001$ \\
\hline
\end{tabular}

Data are expressed as median (range).

Refer to the legend of Table 1 for abbreviations.

in men who had fatty liver in 2007-2008 (Table 5). In participants who had fatty liver in $2000(n=358)$, TG in 2000 and change in FBG were significantly lower in participants whose fatty livers had regressed by $2007-2008$ in both sexes. Body mass index in $2000, \%$ change in BMI, percentage body fat in $2000, \%$ change in percentage body fat, and UA in 2000 were lower in men whose fatty livers had regressed by 2007-2008. Also, the development of "tentative metabolic syndrome" was less common in men whose fatty livers had regressed by 2007-2008. Nondrinkers were less common in women whose fatty livers had regressed by 2007-2008 (Table 6). 


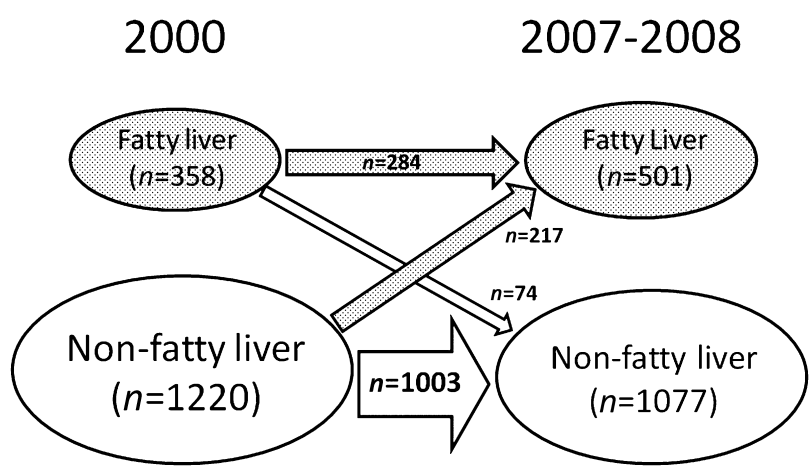

Fig. 1. Number of participants with fatty liver and non-fatty liver in 2000 and 2007-2008 $(n=1578)$

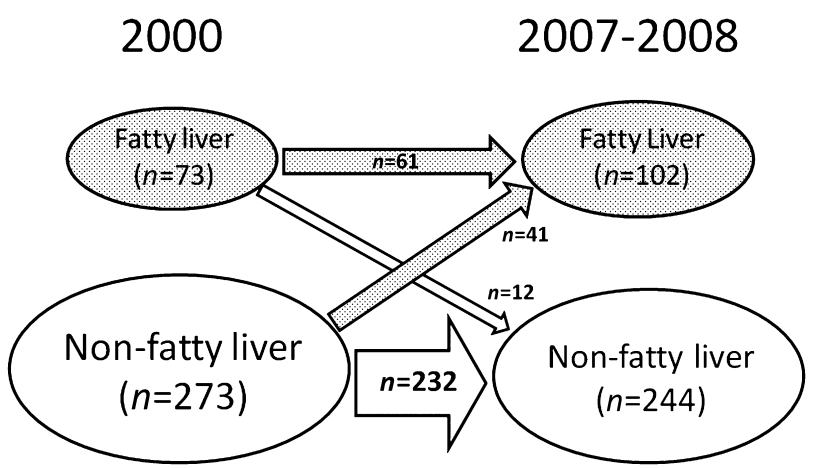

Fig. 2. Number of participants who were classified as nondrinkers with fatty liver and non-fatty liver in 2000 and 2007-2008 $(n=346)$

Table 4. Comparison of clinical and laboratory features of fatty liver and non-fatty liver in 2007-2008 in participants who were classified as non-drinkers $(n=346)$

\begin{tabular}{|c|c|c|c|}
\hline Feature & $\begin{array}{l}\text { Fatty liver } \\
(n=102)\end{array}$ & $\begin{array}{l}\text { Non-fatty liver } \\
(n=244)\end{array}$ & $p$ \\
\hline Men/women & $59 / 43$ & $96 / 148$ & 0.002 \\
\hline Age (years) & $55(42-65)$ & $54(35-63)$ & 0.359 \\
\hline Physical exercise habit (yes/no) & $17 / 83$ & $72 / 170$ & 0.034 \\
\hline BMI $\left(\mathrm{kg} / \mathrm{m}^{2}\right)$ & $25.2(19.4-45.2)$ & $21.6(16.2-32.8)$ & $<0.001$ \\
\hline$\%$ fat volume (men) & $24.5(19.0-34.6)$ & $19.8(10.6-30.7)$ & $<0.001$ \\
\hline$\%$ fat volume (women) & $34.5(25.3-53.8)$ & $26.5(14.3-40.6)$ & $<0.001$ \\
\hline $\mathrm{SBP}(\mathrm{mmHg})$ & $123(91-161)$ & $118(82-177)$ & 0.002 \\
\hline DBP (mmHg) & $73.5(58-93)$ & $70(48-103)$ & 0.001 \\
\hline AST (IU/L) (NV: 13-33) & $23(12-91)$ & $20(11-61)$ & $<0.001$ \\
\hline ALT (IU/L) (NV: 8-42) & $30(11-112)$ & $17(5-69)$ & $<0.001$ \\
\hline GGTP (IU/L) (NV: 10-47) & $33(12-140)$ & $19(9-534)$ & $<0.001$ \\
\hline T.Chol. (mg/dL) (NV: 130-219) & $216(163-370)$ & $213.5(119-319)$ & 0.360 \\
\hline TG (mg/dL) (NV: 46-149) & $118(49-349)$ & $80(30-484)$ & $<0.001$ \\
\hline $\mathrm{UA}(\mathrm{mg} / \mathrm{dL})(\mathrm{NV}: 2.6-7.5)$ & $5.5(3.1-9.3)$ & $4.8(2.2-8.6)$ & $<0.001$ \\
\hline FBG (mg/dL) (NV: 70-109) & $102(76-175)$ & $94(66-129)$ & $<0.001$ \\
\hline Tentative metabolic syndrome (present/absent) & $21 / 81$ & $1 / 243$ & $<0.001$ \\
\hline Receiving treatment for HT, DL, and/or DM (yes/no) & $32 / 70$ & $42 / 202$ & 0.003 \\
\hline
\end{tabular}

Age, BMI, \% fat volume, biochemical and blood pressure data are expressed as median (range).

$\mathrm{NV}$, normal value. Refer to the legend of Table 1 for other abbreviations.

In participants who were classified as non-drinkers and who did not have fatty liver in $2000(n=273)$, body mass index in $2000, \%$ change in BMI, percentage body fat in 2000 , and $\%$ change in percentage body fat were significantly higher in participants who had fatty liver in 2007 2008 in both sexes. Total cholesterol and TG in 2000 were also higher in men who had fatty liver in 2007-2008. In women, change in TG and UA were higher in participants who had fatty liver in 2007-2008 (Table 7). In participants who were classified as non-drinkers and who had fatty liver in $2000(n=73), \%$ change in BMI, $\%$ change in percentage body fat, and change in FBG were significantly lower in men whose fatty livers regressed in 2007-2008. Because there were only two women whose fatty livers regressed in 2007-2008, statistical analysis between features of fatty and non-fatty liver participants in 2007-2008 could not sufficiently performed in women (Table 8 ). 
Table 5. Comparison of clinical and laboratory features of fatty liver and non-fatty liver in 2007-2008 in participants who did not have fatty liver in $2000(n=1220)$

\begin{tabular}{|c|c|c|c|c|c|c|}
\hline \multirow[b]{2}{*}{ Feature } & \multicolumn{2}{|c|}{$\operatorname{Men}(n=891)$} & \multirow[b]{2}{*}{$p$} & \multicolumn{2}{|c|}{ Women $(n=329)$} & \multirow[b]{2}{*}{$p$} \\
\hline & $\begin{array}{l}\text { Fatty liver } \\
\text { in } 2007-2008 \\
(n=177)\end{array}$ & $\begin{array}{l}\text { Non-fatty liver } \\
\text { in 2007-2008 } \\
(n=714)\end{array}$ & & $\begin{array}{l}\text { Fatty liver } \\
\text { in } 2007-2008 \\
(n=40)\end{array}$ & $\begin{array}{l}\text { Non-fatty liver } \\
\text { in 2007-2008 } \\
(n=289)\end{array}$ & \\
\hline Age (years) in 2000 & $48(34-61)$ & $48(34-62)$ & 0.121 & $47(36-53)$ & $46(29-58)$ & 0.367 \\
\hline Alcohol in 2000 (drinker/non-drinker) & $119 / 58$ & $508 / 206$ & 0.307 & $4 / 36$ & $30 / 259$ & 0.941 \\
\hline $\begin{array}{l}\text { Alcohol behavior } \\
\text { (non-drinker/continuous/former drinker/others) }\end{array}$ & $19 / 115 / 1 / 36$ & $86 / 482 / 11 / 117$ & 0.552 & $22 / 3 / 1 / 13$ & $146 / 28 / 2 / 108$ & 0.751 \\
\hline Physical exercise habit (yes/no) & $59 / 116$ & $278 / 430$ & 0.375 & $11 / 29$ & $102 / 186$ & 0.572 \\
\hline BMI $\left(\mathrm{kg} / \mathrm{m}^{2}\right)$ in 2000 & $23.4(18.5-32.8)$ & $22.3(16.5-28.3)$ & $<0.001$ & $22.9(18.4-28.8)$ & $21.0(14.8-28.6)$ & $<0.001$ \\
\hline$\%$ change in BMI* & $+4.6(-10.3-+18.9)$ & $+1.0(-14.2-+22.6)$ & $<0.001$ & $+6.8(-9.2-+38.8)$ & $+0.5(-17.7-+19.9)$ & $<0.001$ \\
\hline$\%$ fat volume in 2000 & $22.6(14.0-32.0)$ & $20.7(9.2-35.6)$ & $<0.001$ & $30.5(22.2-39.3)$ & $25.7(11.5-41.0)$ & $<0.001$ \\
\hline$\%$ change in $\%$ fat volume* & $+7.7(-38.1-+66.2)$ & $-0.5(-47.1-+75.4)$ & $<0.001$ & $+9.0(-18.5-+84.2)$ & $+0.3(-42.6-+106.0)$ & $<0.001$ \\
\hline SBP $(\mathrm{mmHg})$ in 2000 & $124(88-199)$ & $121(83-165)$ & 0.003 & $120(85-176)$ & $115(79-163)$ & 0.085 \\
\hline Change in SBP $(\mathrm{mmHg})^{* *}$ & $+1(-53-+43)$ & $+1(-48-+49)$ & 0.655 & $-1(-42-+58)$ & $+2(-38-+42)$ & 0.440 \\
\hline $\mathrm{DBP}(\mathrm{mmHg})$ in 2000 & $77(56-121)$ & $77(47-100)$ & 0.061 & $74.5(53-114)$ & $71(43-100)$ & 0.213 \\
\hline Change in DBP $(\mathrm{mmHg})^{* *}$ & $-1(-32-+27)$ & $-2(-40-+26)$ & 0.436 & $-1.5(-20-+16)$ & $-1(-28-+25)$ & 0.435 \\
\hline T.Chol. (mg/dL) in 2000 & $212(142-298)$ & $202(123-334)$ & 0.003 & $205(159-314)$ & $205(106-321)$ & 0.669 \\
\hline Change in T.Chol. $(\mathrm{mg} / \mathrm{dL})^{* *}$ & $+10(-107-+87)$ & $+6(-159-+91)$ & 0.065 & $+26(-103-+112)$ & $+19(-109-+98)$ & 0.202 \\
\hline $\mathrm{TG}(\mathrm{mg} / \mathrm{dL})$ in 2000 & $119(42-656)$ & $88.5(26-1516)$ & $<0.001$ & $76(40-166)$ & $63(22-236)$ & 0.002 \\
\hline Change in TG $(\mathrm{mg} / \mathrm{dL})^{* *}$ & $+20(-425-+323)$ & $+7(-535-+831)$ & $<0.001$ & $+20.5(-58-+167)$ & $+14(-73-+192)$ & 0.065 \\
\hline $\mathrm{UA}(\mathrm{mg} / \mathrm{dL})$ in 2000 & $5.7(2.8-8.7)$ & $5.7(1.7-9.5)$ & 0.146 & $4.2(2.0-7.4)$ & $4.1(1.7-7.5)$ & 0.713 \\
\hline Change in UA $(\mathrm{mg} / \mathrm{dL})^{* *}$ & $+0.6(-3.7-+3.2)$ & $+0.3(-3.4-+4.0)$ & $<0.001$ & $+0.8(-1.1-+2.1)$ & $+0.3(-1.5-+2.3)$ & $<0.001$ \\
\hline FBG $(\mathrm{mg} / \mathrm{dL})$ in 2000 & $94(65-158)$ & $94(75-203)$ & 0.550 & $90(78-132)$ & $90(65-120)$ & 0.788 \\
\hline Change in FBG $(\mathrm{mg} / \mathrm{dL})^{* *}$ & $+8(-12-+80)$ & $+5(-58-+82)$ & $<0.001$ & $+7(-13-+42)$ & $+2(-19-+76)$ & 0.014 \\
\hline $\begin{array}{l}\text { Tentative metabolic syndrome in } 2000 \\
\text { (present/absent) }\end{array}$ & $2 / 175$ & $13 / 701$ & 0.523 & $1 / 39$ & $2 / 287$ & 0.323 \\
\hline $\begin{array}{l}\text { Change in tentative metabolic syndrome } \\
\text { between } 2000 \text { and } 2007-2008 \\
\text { (present-present/present-absent/absent-present/ } \\
\text { absent-absent) }\end{array}$ & $2 / 0 / 26 / 149$ & $6 / 7 / 17 / 684$ & $<0.001$ & $1 / 0 / 3 / 36$ & $2 / 0 / 0 / 287$ & $<0.001$ \\
\hline $\begin{array}{l}\text { Receiving treatment for HT, DL, and/or DM } \\
\text { (yes/no) }\end{array}$ & $59 / 118$ & $181 / 533$ & 0.032 & $10 / 30$ & $39 / 250$ & 0.055 \\
\hline
\end{tabular}

* \% change was calculated as follows: $\{[($ data in 2007-2008) - (data in 2000)] / data in 2000$\} \times 100$.

** Change was calculated as follows: (data in 2007-2008) - (data in 2000).

Age, BMI, \% fat volume, biochemical and blood pressure data are expressed as median (range).

Refer to the legend of Table 1 for abbreviations.

Independent predictors for the development or regression of fatty liver in 2007-2008 by logistic regression analysis

The logistic regression analysis showed that high percentage body fat in 2000 , increase in UA, and positive $\%$ change in percentage body fat were independent predictors for the development of fatty liver in 2007-2008 in both sexes. In addition, positive \% change in BMI, increase in FBG, and high serum levels of T.Chol. and TG were independent predictors for the development of fatty liver in 2007-2008 in men. Negative \% change in BMI and low $\mathrm{BMI}$ in 2000 were independent predictors for the regression of fatty liver in 2007-2008 in men, and a decrease in FBG was an independent predictor for the regression of fatty liver in 2007-2008 in women (Table 9).

In participants who were classified as non-drinkers, positive $\%$ change in BMI and high percentage body fat in 2000 were independent predictors for the development of fatty liver in 2007-2008 in men and women, respectively. Negative \% change in BMI and decrease in FBG were independent predictors for the regression of fatty liver in 2007-2008 in men (Table 9).

\section{Discussion}

The relation between fatty liver and metabolic syndromerelated disorders such as obesity is well known, but data from longitudinal observation (with sufficient duration) of individuals in a large population are hitherto sparse. Kojima et al. [5] reported that 5088 (14.3\%) of 35519 participants developed fatty liver, and that fatty liver resolved in 1248 (3.5\%) of those participants during the follow-up period from 1989 to 2000 . They further reported that BMI, as well as the relative change in BMI in each individual, was related to the onset of fatty liver, followed by serum levels of TG 
Table 6. Comparison of clinical and laboratory features of fatty liver and non-fatty liver in 2007-2008 in participants who had fatty liver in $2000(n=358)$

\begin{tabular}{|c|c|c|c|c|c|c|}
\hline \multirow[b]{2}{*}{ Feature } & \multicolumn{2}{|c|}{$\operatorname{Men}(n=317)$} & \multirow[b]{2}{*}{$p$} & \multicolumn{2}{|c|}{ Women $(n=41)$} & \multirow[b]{2}{*}{$p$} \\
\hline & $\begin{array}{l}\text { Fatty liver } \\
\text { in } 2007-2008 \\
(n=250)\end{array}$ & $\begin{array}{l}\text { Non-fatty liver } \\
\text { in } 2007-2008 \\
(n=67)\end{array}$ & & $\begin{array}{l}\text { Fatty liver } \\
\text { in } 2007-2008 \\
(n=34)\end{array}$ & $\begin{array}{l}\text { Non-fatty liver } \\
\text { in } 2007-2008 \\
(n=7)\end{array}$ & \\
\hline Age (years) in 2000 & $47(34-58)$ & $47(35-54)$ & 0.889 & $47(35-56)$ & $46(39-50)$ & 0.282 \\
\hline Alcohol in 2000 (drinker/non-drinker) & $158 / 92$ & $50 / 17$ & 0.080 & $1 / 33$ & $3 / 4$ & 0.012 \\
\hline $\begin{array}{l}\text { Alcohol behavior } \\
\text { (non-drinker/continuous/former drinker/others) }\end{array}$ & $40 / 149 / 3 / 49$ & $10 / 44 / 1 / 7$ & 0.321 & $12 / 0 / 1 / 21$ & $2 / 0 / 3 / 2$ & 0.005 \\
\hline Physical exercise habit (yes/no) & $66 / 182$ & $16 / 51$ & 0.689 & $2 / 32$ & $2 / 5$ & 0.128 \\
\hline BMI $\left(\mathrm{kg} / \mathrm{m}^{2}\right)$ in 2000 & $25.4(19.1-45.1)$ & $24.6(19.1-29.8)$ & 0.002 & $26.1(21.5-41.3)$ & $24.7(21.1-27.6)$ & 0.198 \\
\hline$\%$ change in $\mathrm{BMI} *$ & $+2.3(-20.0-+18.7)$ & $-1.8(-14.1-+9.6)$ & $<0.001$ & $+3.0(-10.4-+14.0)$ & $-0.1(-9.1-+5.8)$ & 0.125 \\
\hline$\%$ fat volume in 2000 & $25.8(14.8-52.6)$ & $24.2(17.1-33.0)$ & 0.012 & $35.8(18.4-49.8)$ & $31.6(26.2-38.9)$ & 0.144 \\
\hline$\%$ change in $\%$ fat volume* & $+1.5(-41.4-+63.6)$ & $-4.7(-32.5-+66.3)$ & $<0.001$ & $+2.2(-25.7-+84.8)$ & $+5.2(-25.3-+9.3)$ & 0.879 \\
\hline SBP $(\mathrm{mmHg})$ in 2000 & $128(79-171)$ & $124(79-161)$ & 0.608 & $127(98-162)$ & $129(105-153)$ & 0.879 \\
\hline Change in SBP $(\mathrm{mmHg})^{* *}$ & $-1(-58-+43)$ & $-3(-55-+24)$ & 0.326 & $-4(-50-+25)$ & $-7(-39-+6)$ & 0.672 \\
\hline $\mathrm{DBP}(\mathrm{mmHg})$ in 2000 & $80(43-107)$ & $80(51-107)$ & 0.691 & $79(58-100)$ & 77 (67-93) & 0.906 \\
\hline Change in DBP $(\mathrm{mmHg})^{* *}$ & $-4(-38-+30)$ & $-5(-32-+21)$ & 0.900 & $-5.5(-28-+13)$ & $-3(-30-+2)$ & 0.959 \\
\hline T.Chol. (mg/dL) in 2000 & $214(140-320)$ & $209(142-317)$ & 0.635 & $221(136-271)$ & $211(178-248)$ & 0.599 \\
\hline Change in T.Chol. $(\mathrm{mg} / \mathrm{dL})^{* *}$ & $\pm 0(-107-+87)$ & $-7(-79-+54)$ & 0.241 & $+9(-90-+73)$ & $+7(-28-+76)$ & 0.959 \\
\hline $\mathrm{TG}(\mathrm{mg} / \mathrm{dL})$ in 2000 & $154(36-586)$ & $110(48-753)$ & 0.009 & $128(49-336)$ & $73(40-132)$ & 0.041 \\
\hline Change in TG $(\mathrm{mg} / \mathrm{dL})^{* *}$ & $\pm 0(-378-+713)$ & $-6(-545-+279)$ & 0.400 & $+1.5(-210-+193)$ & $\pm 0(-6-+18)$ & 0.826 \\
\hline $\mathrm{UA}(\mathrm{mg} / \mathrm{dL})$ in 2000 & $6.4(0.7-10.1)$ & $6.0(2.9-8.3)$ & 0.017 & $4.9(3.1-6.2)$ & $4.2(3.4-6.2)$ & 0.799 \\
\hline Change in UA $(\mathrm{mg} / \mathrm{dL})^{* *}$ & $+0.2(-5.8-+4.1)$ & $\pm 0(-1.8-+1.8)$ & 0.201 & $+0.4(-1.2-+2.6)$ & $+0.5(-0.2-+1.5)$ & 0.826 \\
\hline $\mathrm{FBG}(\mathrm{mg} / \mathrm{dL})$ in 2000 & $98.5(76-243)$ & $99(80-197)$ & 0.208 & $96.5(77-128)$ & $96(88-111)$ & 0.747 \\
\hline Change in FBG $(\mathrm{mg} / \mathrm{dL})^{* *}$ & $+8(-125-+87)$ & $+3(-32-+31)$ & 0.001 & $+7(-10-+63)$ & $-1(-16-+4)$ & 0.003 \\
\hline $\begin{array}{l}\text { Tentative metabolic syndrome in } 2000 \\
\text { (present/absent) }\end{array}$ & $53 / 197$ & $11 / 56$ & 0.387 & $2 / 32$ & $0 / 7$ & 1.000 \\
\hline $\begin{array}{l}\text { Change in tentative metabolic syndrome between } \\
2000 \text { and } 2007-2008 \\
\text { (present-present/present-absent/absent-present/ } \\
\text { absent-absent) }\end{array}$ & $43 / 10 / 47 / 150$ & $5 / 6 / 3 / 53$ & 0.001 & $2 / 0 / 7 / 25$ & $0 / 0 / 0 / 7$ & 0.305 \\
\hline Receiving treatment for HT, DL, and/or DM (yes/no) & $102 / 148$ & $23 / 44$ & 0.336 & $14 / 20$ & $2 / 5$ & 0.534 \\
\hline
\end{tabular}

Refer to the legends of Table 1 and 5 for abbreviations.

and FBG in both sexes, and that alcohol intake did not have any relation to the onset of fatty liver, in contrast with the data from the Dionysos study [11]. Our present results were partly in line with these findings, because 217 (13.8\%) of 1578 participants developed fatty liver, which resolved in 74 (4.7\%) participants, and the logistic regression analysis revealed that alcohol consumption was not a predictor for the development of fatty liver as previously reported [8, 12]. However, in contrast with the results by Kojima et al. [5], not BMI but high percentage body fat in 2000 and increased $\%$ change in percentage body fat during the follow-up period in each participant were independent predictors for the development of fatty liver in both sexes in the present study. Eguchi et al. [13] reported that hepatic fat infiltration in NAFLD might be influenced by visceral fat accumulation regardless of BMI. Imamura et al. [14] also reported that altered body composition, particularly increased percentage body fat without an increase in BMI, was strongly associated with the increasing prevalence of fatty liver.

Indeed, the change in BMI between 2000 and 2007-2008 was constantly associated with the development and regression of fatty liver in men regardless of the history of alcohol intake in the present study. In contrast, in women, a high percentage body fat in 2000 was associated with the development of fatty liver in 2007-2008 regardless of alcohol consumption. The BMI is chosen as a measure of overall adiposity and elevated percentage body fat with normal BMI can be presumed to reflect central body fat distribution [8]. Lonardo et al. [12] reported that women with fatty liver had a more central fat distribution, which reflects visceral fat, than women without fatty liver, and concluded that this central-type body fat distribution predicted fatty liver only in women. Our results support these data and sex differences in the pathogenesis and treatment of fatty liver, particularly NAFLD, should be further determined.

Metabolic syndrome-related disorders with abnormal serum levels of T.Chol., TG, UA, and FBG were associated with the development or regression of fatty liver in men and women with or without alcohol intake in the present study. 
Table 7. Comparison of clinical and laboratory features of fatty liver and non-fatty liver in 2007-2008 in participants who were classified as non-drinkers and who did not have fatty liver in $2000(n=273)$

\begin{tabular}{|c|c|c|c|c|c|c|}
\hline \multirow[b]{2}{*}{ Feature } & \multicolumn{2}{|c|}{$\operatorname{Men}(n=105)$} & \multirow[b]{2}{*}{$p$} & \multicolumn{2}{|c|}{ Women $(n=168)$} & \multirow[b]{2}{*}{$p$} \\
\hline & $\begin{array}{l}\text { Fatty liver } \\
\text { in } 2007-2008 \\
(n=19)\end{array}$ & $\begin{array}{l}\text { Non-fatty liver } \\
\text { in } 2007-2008 \\
(n=86)\end{array}$ & & $\begin{array}{l}\text { Fatty liver } \\
\text { in } 2007-2008 \\
(n=22)\end{array}$ & $\begin{array}{l}\text { Non-fatty liver } \\
\text { in } 2007-2008 \\
(n=146)\end{array}$ & \\
\hline Age (years) in 2000 & $49(34-55)$ & $48(34-56)$ & 0.809 & $47(36-53)$ & $46(29-55)$ & 0.409 \\
\hline Physical exercise habit (yes/no) & $3 / 15$ & $32 / 53$ & 0.120 & $6 / 16$ & $40 / 105$ & 0.927 \\
\hline $\operatorname{BMI}\left(\mathrm{kg} / \mathrm{m}^{2}\right)$ in 2000 & $23.2(19.9-25.7)$ & $21.4(16.5-26.2)$ & 0.003 & $22.5(19.8-26.4)$ & $21.4(16.5-28.6)$ & 0.001 \\
\hline$\%$ change in $\mathrm{BMI}^{*}$ & $+4.3(-1.9-+17.4)$ & $+1.0(-8.4-+22.6)$ & 0.006 & $+6.8(-2.7-+19.6)$ & $\pm 0(-17.7-+19.9)$ & $<0.001$ \\
\hline$\%$ fat volume in 2000 & $20.9(17.7-31.3)$ & $18.7(9.6-35.6)$ & 0.006 & $30.4(23.6-37.6)$ & $25.9(16.7-35.6)$ & $<0.001$ \\
\hline$\%$ change in $\%$ fat volume* & $+8.5(-6.4-+30.9)$ & $-0.5(-29.7-+61.1)$ & 0.016 & $+10.4(-5.9-+38.0)$ & $-0.8(-33.9-+106.0)$ & $<0.001$ \\
\hline $\mathrm{SBP}(\mathrm{mmHg})$ in 2000 & $117(100-140)$ & $114(83-149)$ & 0.206 & $119.5(85-158)$ & $115(79-163)$ & 0.342 \\
\hline Change in SBP $(\mathrm{mmHg})^{* *}$ & $+4(-15-+23)$ & $+2(-32-+32)$ & 0.963 & $-1(-42-+58)$ & $+2(-38-+38)$ & 0.457 \\
\hline $\mathrm{DBP}(\mathrm{mmHg})$ in 2000 & $73(57-89)$ & $72(47-94)$ & 0.405 & $72.5(53-88)$ & $71(43-100)$ & 0.544 \\
\hline Change in DBP $(\mathrm{mmHg})^{* *}$ & $-3(-19-+8)$ & $-1(-17-+22)$ & 0.191 & $-1.5(-20-+16)$ & $-2(-28-+20)$ & 0.432 \\
\hline T.Chol. (mg/dL) in 2000 & $212(183-255)$ & $196.5(133-328)$ & 0.021 & $208(162-307)$ & $204.5(106-309)$ & 0.485 \\
\hline Change in T.Chol. $(\mathrm{mg} / \mathrm{dL})^{* *}$ & $+10(-42-+33)$ & $+4(-159-+77)$ & 0.191 & $+26(-67-+112)$ & $+19(-44-+97)$ & 0.231 \\
\hline $\mathrm{TG}(\mathrm{mg} / \mathrm{dL})$ in 2000 & $116(47-242)$ & $81(26-545)$ & 0.001 & $67.5(48-166)$ & $63.5(27-221)$ & 0.210 \\
\hline Change in TG $(\mathrm{mg} / \mathrm{dL})^{* *}$ & $+13(-54-+117)$ & $+10(-382-+181)$ & 0.606 & $+29.5(-42-+167)$ & $+12.5(-63-+192)$ & 0.035 \\
\hline $\mathrm{UA}(\mathrm{mg} / \mathrm{dL})$ in 2000 & $5.8(2.8-8.7)$ & $5.3(2.1-7.8)$ & 0.053 & $4.2(2.0-6.6)$ & $4.1(2.3-7.5)$ & 0.974 \\
\hline Change in UA $(\mathrm{mg} / \mathrm{dL})^{* *}$ & $+0.6(-0.2-+1.6)$ & $+0.2(-2.3-+2.8)$ & 0.058 & $+1.1(-0.6-+1.8)$ & $+0.4(-1.1-+2.3)$ & 0.004 \\
\hline $\mathrm{FBG}(\mathrm{mg} / \mathrm{dL})$ in 2000 & $95(79-102)$ & $90(78-108)$ & 0.141 & $90(78-132)$ & $91(65-120)$ & 0.693 \\
\hline Change in FBG $(\mathrm{mg} / \mathrm{dL})^{* *}$ & $+6(-5-+22)$ & $+4(-14-+24)$ & 0.431 & $+5.5(-9-+42)$ & $+2(-19-+76)$ & 0.073 \\
\hline $\begin{array}{l}\text { Tentative metabolic syndrome in } 2000 \\
\text { (present/absent) }\end{array}$ & $0 / 19$ & $0 / 86$ & - & $1 / 21$ & $0 / 146$ & 0.131 \\
\hline $\begin{array}{l}\text { Change in tentative metabolic syndrome between } \\
2000 \text { and } 2007-2008 \\
\text { (present-present/present-absent/absent-present/ } \\
\text { absent-absent) }\end{array}$ & $0 / 0 / 2 / 17$ & $0 / 0 / 1 / 85$ & 0.084 & $1 / 0 / 0 / 21$ & $0 / 0 / 0 / 146$ & 0.131 \\
\hline Receiving treatment for HT, DL, and/or DM (yes/no) & $2 / 17$ & $17 / 69$ & 0.515 & $6 / 16$ & $23 / 123$ & 0.183 \\
\hline
\end{tabular}

Refer to the legends of Table 1 and 5 for abbreviations.

However, the presence of "tentative metabolic syndrome" was not an independent predictor for the development or regression of fatty liver. Hamaguchi et al. [6] studied 4401 Japanese adults, and $308(7.0 \%)$ of those participants developed fatty liver, which resolved in 113 (2.6\%) participants during the mean follow-up period of 414 days. In their study population, the presence of metabolic syndrome at baseline was one of the independent predictors for the development and regression of fatty liver in both sexes. One possible explanation for these discrepant results may be the difference in diagnostic criteria of the metabolic syndromes. In contrast with the ATP III criteria [15], which were adopted by Hamaguchi et al. [6], the Japanese criteria for the diagnosis of metabolic syndrome adopted in the present study defined the presence of central obesity (waist circumference) as a pre-requisite and indispensable factor [10]. Because waist circumference was not available in our study subjects, we followed the method used by Hamaguchi et al. [6] and substituted a BMI $\geq 25 \mathrm{~kg} / \mathrm{m}^{2}$ instead of waist circumference. However, if the participants were not overweight as judged by BMI, they failed to be included in the group of subjects with "tentative metabolic syndrome". Since
International Diabetes Federation also proposed central obesity (waist circumference) as an indispensable factor for the diagnosis of metabolic syndrome [16], detailed evaluation of metabolic syndrome including the measurement of waist circumference should be performed in the near future.

Blood pressures, both SBP and DBP, and physical activity were not independent predictors for the development or regression of fatty liver in our study population. Donati et al. [17] reported that insulin resistance, a factor independently associated with fatty liver, was predicted by the presence of arterial hypertension in non-obese, non-diabetic, non-heavy alcohol drinking patients with arterial hypertensive and normal liver enzymes. Akahoshi et al. [18] also reported that non-obese male participants with fatty liver had the highest odds ratio for hypertension. Unfortunately, we did not perform such analysis, and the discrepancy between these results and ours is unclear. The association between arterial hypertension or physical activity and fatty liver remains uncertain and requires further investigation. Physical activity may also reduce the associated risk factors and prevent the progression of fatty liver, especially NAFLD, but the independent contribution on variations in liver fat is so far 
Table 8. Comparison of clinical and laboratory features of fatty liver and non-fatty liver in 2007-2008 in participants who were classified as non-drinkers and who had fatty liver in $2000(n=73)$

\begin{tabular}{|c|c|c|c|c|c|c|}
\hline \multirow[b]{2}{*}{ Feature } & \multicolumn{2}{|c|}{$\operatorname{Men}(n=50)$} & \multirow[b]{2}{*}{$p$} & \multicolumn{2}{|c|}{ Women $(n=23)$} & \multirow[b]{2}{*}{$p$} \\
\hline & $\begin{array}{l}\text { Fatty liver } \\
\text { in } 2007-2008 \\
(n=40)\end{array}$ & $\begin{array}{l}\text { Non-fatty liver } \\
\text { in } 2007-2008 \\
(n=10)\end{array}$ & & $\begin{array}{l}\text { Fatty liver } \\
\text { in } 2007-2008 \\
(n=21)\end{array}$ & $\begin{array}{l}\text { Non-fatty liver } \\
\text { in 2007-2008 } \\
(n=2)\end{array}$ & \\
\hline Age (years) in 2000 & $47(35-57)$ & $47.5(35-54)$ & 0.747 & $47(35-56)$ & $48.5(47-50)$ & 0.711 \\
\hline Physical exercise habit (yes/no) & $6 / 33$ & $0 / 10$ & 0.362 & $2 / 19$ & $0 / 2$ & 1.000 \\
\hline BMI $\left(\mathrm{kg} / \mathrm{m}^{2}\right)$ in 2000 & $25.6(22.2-31.6)$ & $24.7(21.6-27.7)$ & 0.511 & $24.3(21.7-41.3)$ & $23.6(21.5-25.7)$ & 0.332 \\
\hline$\%$ change in $\mathrm{BMI} *$ & $+3.0(-7.9-+18.4)$ & $-1.5(-14.1-+2.8)$ & 0.004 & $+2.1(-10.4-+14.0)$ & $+2.3(-0.1-+4.7)$ & 0.870 \\
\hline$\%$ fat volume in 2000 & $24.3(17.8-34.2)$ & $23.9(18.4-32.7)$ & 0.839 & $36.1(28.8-49.1)$ & $31.1(26.2-36.0)$ & 0.285 \\
\hline$\%$ change in $\%$ fat volume* & $+4.5(-20.2-+63.6)$ & $-4.3(-22.0-+20.7)$ & 0.020 & $+0.2(-25.7-+21.5)$ & $+2.2(-3.1-+7.5)$ & 0.711 \\
\hline $\mathrm{SBP}(\mathrm{mmHg})$ in 2000 & $122.5(93-160)$ & $120(112-156)$ & 0.896 & $125(98-159)$ & $148(143-153)$ & 0.198 \\
\hline Change in SBP $(\mathrm{mmHg})^{* *}$ & $+3.5(-41-+31)$ & $-1.5(-27-+24)$ & 0.296 & $-7(-46-+25)$ & $-14.5(-32-+3)$ & 0.640 \\
\hline $\mathrm{DBP}(\mathrm{mmHg})$ in 2000 & $77(63-102)$ & $77(56-87)$ & 0.711 & $77(58-100)$ & $85(77-93)$ & 0.569 \\
\hline Change in DBP $(\mathrm{mmHg})^{* *}$ & $-1.5(-17-+17)$ & $-5(-19-+21)$ & 0.693 & $-5(-28-+13)$ & $-8.5(-9-8)$ & 0.387 \\
\hline T.Chol. (mg/dL) in 2000 & $211(152-302)$ & $198.5(181-257)$ & 0.465 & $204(136-271)$ & $233(218-248)$ & 0.640 \\
\hline Change in T.Chol. $(\mathrm{mg} / \mathrm{dL})^{* *}$ & $+9(-107-+68)$ & $+2(-40-+54)$ & 0.896 & $+9(-90-+61)$ & $-5.5(-22-+11)$ & 0.569 \\
\hline $\mathrm{TG}(\mathrm{mg} / \mathrm{dL})$ in 2000 & $128.5(46-414)$ & $104(48-271)$ & 0.319 & $128(49-336)$ & $68(40-96)$ & 0.198 \\
\hline Change in TG $(\mathrm{mg} / \mathrm{dL})^{* *}$ & $+7.5(-214-+251)$ & $+1(-75-+213)$ & 0.933 & $-5(-210-+53)$ & $+12.5(+7-+18)$ & 0.387 \\
\hline $\mathrm{UA}(\mathrm{mg} / \mathrm{dL})$ in 2000 & $6.2(3.5-8.5)$ & $5.8(3.8-7.3)$ & 0.465 & $4.8(3.1-6.2)$ & $3.85(3.5-4.2)$ & 0.237 \\
\hline Change in UA $(\mathrm{mg} / \mathrm{dL})^{* *}$ & $+0.2(-3.6-+3.0)$ & $-0.1(-0.9-+1.3)$ & 0.711 & $+0.3(-1.2-+1.2)$ & $+1.2(+0.9-+1.5)$ & 0.071 \\
\hline $\mathrm{FBG}(\mathrm{mg} / \mathrm{dL})$ in 2000 & $98.5(81-140)$ & $97(87-161)$ & 0.877 & $98(83-122)$ & $96(96-96)$ & 0.870 \\
\hline Change in FBG $(\mathrm{mg} / \mathrm{dL})^{* *}$ & $+10(-14-+70)$ & $-1.5(-32-+12)$ & 0.001 & $+7(-10-+40)$ & $-2(-4- \pm 0)$ & 0.158 \\
\hline $\begin{array}{l}\text { Tentative metabolic syndrome in } 2000 \\
\text { (present/absent) }\end{array}$ & $8 / 32$ & $1 / 9$ & 0.665 & $0 / 21$ & $0 / 2$ & - \\
\hline $\begin{array}{l}\text { Change in tentative metabolic syndrome between } \\
2000 \text { and } 2007-2008 \\
\text { (present-present/present-absent/absent-present/ } \\
\text { absent-absent) }\end{array}$ & $6 / 2 / 8 / 24$ & $0 / 1 / 0 / 9$ & 0.177 & $0 / 0 / 4 / 17$ & $0 / 0 / 0 / 2$ & 1.000 \\
\hline Receiving treatment for HT, DL, and/or DM (yes/no) & $15 / 25$ & $1 / 9$ & 0.138 & $9 / 12$ & $1 / 1$ & 1.000 \\
\hline
\end{tabular}

Refer to the legends of Table 1 and 5 for abbreviations.

unknown [19, 20]. In our study, there was a limitation because self-reported information regarding habitual physical activity, as well as alcohol consumption, can lead to underor over-reporting. A direct interview by trained medical staff should have been performed to get accurate information from individuals.

In conclusion, BMI and percentage body fat were strongly associated with the development or regression of fatty liver regardless of the history of alcohol intake in the present study. Metabolic syndrome-related disorders such as serum levels of T.Chol., TG, UA, and FBG were also associated with such clinical features in some degree. Although most patients with NAFLD have a benign clinical course [21], the presence of multiple metabolic disorders can be associated with potentially progressive and severe liver diseases such as non-alcoholic steatohepatitis [22, 23]. Our present data suggest that control of body weight in men and the percentage body fat in women are particularly important for the prevention or treatment of fatty liver, followed by the control of dyslipidemia, hyperuricemia, and hyperglycemia.

\section{References}

[1] Sherlock, S. and Dooley, J.: Diseases of the Liver and Biliary System, 10th ed. Blackwell Science, Oxford, pp. 427-433, 1997.

[2] Sass, D.A., Chang, P., and Chopra, K.B.: Nonalcoholic fatty liver disease: a clinical review. Dig. Dis. Sci., 50, 171-180, 2005.

[3] Nugent, C. and Younossi, Z.M.: Evaluation and management of obesity-related nonalcoholic fatty liver disease. Nat. Clin. Pract. Gastroenterol. Hepatol., 4, 432-441, 2007.

[4] Fan, J.-G., Li, F., Cai, X.-B., Peng, Y.-D., Ao, Q.-H., and Gao, Y.: Effects of nonalcoholic fatty liver disease on the development of metabolic disorders. J. Gastroenterol. Hepatol., 22, 1086-1091, 2007.

[5] Kojima, S., Watanabe, N., Numata, M., Ogawa, T., and Matsuzaki, S.: Increase in the prevalence of fatty liver in Japan over the past 12 years: analysis of clinical background. J. Gastroenterol., 38, 954-961, 2003.

[6] Hamaguchi, M., Kojima, T., Takeda, N., Nakagawa, T., Taniguchi, H., Fujii, K., Omatsu, T., Nakajima, T., Sarui, H., Shimazaki, M., Kato, T., Okuda, J., and Ida, K.: The metabolic syndrome as a predictor of nonalcoholic fatty liver disease. Ann. Intern. Med., 143, 722-728, 2005. 
Table 9. Independent predictors for the development or regression of fatty liver in 2007-2008 by logistic regression analysis

\begin{tabular}{|c|c|c|c|c|c|}
\hline Variables & $\begin{array}{l}\text { Regression } \\
\text { coefficient }\end{array}$ & Standard error & $p$ & Adjusted odds ratio & $95 \% \mathrm{CI}$ \\
\hline \multicolumn{6}{|c|}{ For the development of fatty liver in participants who did not have fatty liver in $2000(n=1220)$} \\
\hline \multicolumn{6}{|c|}{ Men $(n=891)$} \\
\hline$\%$ fat volume in 2000 & 0.144 & 0.036 & $<0.001$ & 1.155 & $1.076-1.239$ \\
\hline$\%$ change in $\mathrm{BMI}^{*}$ & 0.127 & 0.028 & $<0.001$ & 1.135 & $1.074-1.199$ \\
\hline Change in FBG $(\mathrm{mg} / \mathrm{dL})^{* *}$ & 0.030 & 0.009 & 0.001 & 1.030 & $1.012-1.049$ \\
\hline T.Chol. (mg/dL) in 2000 & 0.009 & 0.003 & 0.005 & 1.009 & $1.003-1.015$ \\
\hline Change in UA $(\mathrm{mg} / \mathrm{dL})^{* *}$ & 0.243 & 0.103 & 0.018 & 1.276 & $1.042-1.560$ \\
\hline $\mathrm{TG}(\mathrm{mg} / \mathrm{dL})$ in 2000 & 0.003 & 0.001 & 0.021 & 1.003 & $1.001-1.005$ \\
\hline$\%$ change in $\%$ fat volume* & 0.020 & 0.010 & 0.035 & 1.020 & $1.000-1.040$ \\
\hline \multicolumn{6}{|l|}{ Women $(n=329)$} \\
\hline$\%$ fat volume in 2000 & 0.314 & 0.090 & $<0.001$ & 1.369 & $1.148-1.633$ \\
\hline Change in UA $(\mathrm{mg} / \mathrm{dL})^{* *}$ & 0.788 & 0.313 & 0.012 & 2.199 & $1.191-4.061$ \\
\hline$\%$ change in $\%$ fat volume* & 0.041 & 0.017 & 0.018 & 1.042 & $1.008-1.077$ \\
\hline \multicolumn{6}{|c|}{ For the regression of fatty liver in participants who had non-fatty liver in $2000(n=358)$} \\
\hline \multicolumn{6}{|c|}{$\operatorname{Men}(n=317)$} \\
\hline$\%$ change in BMI* & -0.170 & 0.042 & $<0.001$ & 0.844 & $0.777-0.916$ \\
\hline $\mathrm{BMI}\left(\mathrm{kg} / \mathrm{m}^{2}\right)$ in 2000 & -0.255 & 0.099 & 0.010 & 0.775 & $0.638-0.941$ \\
\hline \multicolumn{6}{|l|}{ Women $(n=41)$} \\
\hline Change in FBG $(\mathrm{mg} / \mathrm{dL})^{* *}$ & -0.290 & 0.139 & 0.036 & 0.748 & $0.570-0.983$ \\
\hline \multicolumn{6}{|c|}{ For the development of fatty liver in participants who were classified as non-drinkers and who did not have fatty liver in $2000(n=273)$} \\
\hline \multicolumn{6}{|c|}{$\operatorname{Men}(n=105)$} \\
\hline$\%$ change in $\mathrm{BMI}^{*}$ & 0.209 & 0.098 & 0.034 & 1.232 & $1.017-1.493$ \\
\hline \multicolumn{6}{|l|}{ Women $(n=168)$} \\
\hline$\%$ fat volume in 2000 & 0.421 & 0.139 & 0.002 & 1.523 & $1.160-2.001$ \\
\hline \multicolumn{6}{|c|}{ For the regression of fatty liver in participants who were classified as non-drinkers and who had fatty liver in $2000(n=73)$} \\
\hline \multicolumn{6}{|c|}{$\operatorname{Men}(n=50)$} \\
\hline Change in FBG $(\mathrm{mg} / \mathrm{dL})^{* *}$ & -0.186 & 0.071 & 0.009 & 0.830 & $0.722-0.954$ \\
\hline$\%$ change in BMI* & -0.351 & 0.174 & 0.044 & 0.704 & $0.501-0.990$ \\
\hline \multicolumn{6}{|l|}{ Women $(n=23)$} \\
\hline Nil & & & & & \\
\hline
\end{tabular}

CI, confidence interval. Refer to the legends of Table 1 and 5 for other abbreviations.

[7] Fujikawa, K., Ohata, K., Honda, T., Miyazoe, S., Ichikawa, T., Ishikawa, H., Hamasaki, K., Nakao, K., Toriyama, K., and Eguchi, K.: Nonalcoholic steatohepatitis with improved hepatic fibrosis after weight reduction. Intern. Med., 43, 289-294, 2004.

[8] Omagari, K., Kadokawa, Y., Masuda, J.-I., Egawa, I., Sawa, T., Hazama, H., Ohba, K., Isomoto, H., Mizuta, Y., Hayashida, K., Murase, K., Kadota, T., Murata, I., and Kohno, S.: Fatty liver in non-alcoholic non-overweight Japanese adults: Incidence and clinical characteristics. $J$. Gastroenterol. Hepatol., 17, 1098-1105, 2002.

[9] World Health Organization.: Obesity and overweight. (http:// www.who.int/mediacentre /factsheets/fs311/en/index.html).

[10] Lee, J.S., Kawakubo, K., Mori, K., and Akabayashi, A.: Effective cut-off values of waist circumference to detect the clustering of cardiovascular risk factors of metabolic syndrome in Japanese men and women. Diabetes Vasc. Dis. Res., 4, 340-345, 2007.

[11] Bedogni, G., Miglioli, L., Masutti, F., Castiglione, A., Croce, L.S., Tiribelli, C., and Bellentani, S.: Incidence and natural course of fatty liver in the general population: The Dionysos study. Hepatology, 46, 1387-1391, 2007.

[12] Lonardo, A. and Trande, P.: Are there any sex differences in fatty liver? A study of glucose metabolism and body fat distribution. J. Gastroenterol. Hepatol., 15, 775-782, 2000.

[13] Eguchi, Y., Eguchi, T., Mizuta, T., Ide, Y., Yasutake, T., Iwakiri, R., Hisatomi, A., Ozaki, I., Yamamoto, K., Kitajima, Y., Kawaguchi, Y., Kuroki, S., and Ono, N.: Visceral fat accumulation and insulin resistance are important factors in nonalcoholic fatty liver disease. J. Gastroenterol., 41, 462- 
469, 2006.

[14] Imamura, Y., Uto, H., Oketani, M., Hiramine, Y., Hosoyamada, K., Sho, Y., Hiwaki, T., Baba, Y., Tahara, K., Kubozono, O., Kusano, K., and Tsubouchi, H.: Association between changes in body composition and the increasing prevalence of fatty liver in Japanese men. Hepatol. Res., 38, 1083-1086, 2008.

[15] Expert Panel on Detection, Evaluation, and Treatment of High Blood Cholesterol in Adult.: Executive summary of the third report of the National Cholesterol Education Program (NCEP) Expert Panel on Detection, Evaluation, and Treatment of High Blood Cholesterol in Adults (Adult Treatment Panel III). JAMA, 285, 2486-2497, 2001.

[16] International Diabetes Federation: IDF Worldwide Definition of the Metabolic Syndrome. (http://www.idf.org/home/ index.cfm?unode=1120071E-AACE-41D2-9FA0BAB6E25BA072).

[17] Donati, G., Stagni, B., Piscaglia, F., Venturoli, N., MorselliLabate, A.M., Rasciti, L., and Bolondi, L.: Increased prevalence of fatty liver in arterial hypertensive patients with normal liver enzymes: role of insulin resistance. Gut, 53, 1020-1023, 2004.

[18] Akahoshi, M., Amasaki, Y., Soda, M., Tominaga, T., Ichimaru,
S., Nakashima, E., Seto, S., and Yano, K.: Correlation between fatty liver and coronary risk factors: a population study of elderly men and women in Nagasaki, Japan. Hypertens. Res., 24, 337-343, 2001.

[19] Spassiani, N.A. and Kuk, J.L.: Exercise and the fatty liver. Appl. Physiol. Nutr. Metab., 33, 802-807, 2008.

[20] Krasnoff, J.B., Painter, P.L., Wallace, J.P., Bass, N.M., and Merriman, R.B.: Health-related fitness and physical activity in patients with nonalcoholic fatty liver disease. Hepatology, 47, 1158-1166, 2008.

[21] Dam-Larsen, S., Franzmann, M., Andersen, I.B., Christoffersen, P., Jensen, L.B., Sorensen, T.I.A., Becker, U., and Bendtsen, F.: Long term prognosis of fatty liver: risk of chronic liver disease and death. Gut, 53, 750-755, 2004.

[22] Marchesini, G., Bugianesi, E., Forlani, G., Cerrelli, F., Lenzi, M., Manini, R., Natale, S., Vanni, E., Villanova, N., Melchionda, N., and Rizzetto, M.: Nonalcoholic fatty liver, steatohepatitis, and the metabolic syndrome. Hepatology, 37, 917-923, 2003.

[23] Shiota, G. and Tsuchiya, H.: Pathophysiology of NASH: insulin resistance, free fatty acids and oxidative stress. $J$. Clin. Biochem. Nutr., 38, 127-132, 2006. 